Check for updates

Cite this: RSC Adv., 2019, 9, 32270

\title{
Optimization of metal-organic (citric acid) frameworks for controlled release of nutrients $\uparrow$
}

\author{
Ke Wu, ${ }^{\text {ab }}$ Changwen Du, (D) *ab Fei Ma, ${ }^{a}$ Yazhen Shen ${ }^{a}$ and Jianmin Zhou ${ }^{a}$
}

Although polymer-coated controlled-release fertilizers have been under development for decades, their high costs, complex production processes, and potential environmental hazards have limited their application. Therefore, it is necessary to design and develop new materials for controlled nutrient release. In this study, two novel MOFs, compounds I and II, were successfully fabricated and optimized using ferric chloride, phosphoric acid, citric acid, and urea under hydrothermal conditions. The N, P, and Fe contents in compound I were $9.05 \%, 14.92 \%$, and $14.55 \%$, respectively, while the corresponding values in compound II were $10.78 \%, 14.10 \%$, and $16.68 \%$. The soil incubation results revealed that both compounds showed good slow-release longevity (more than 100 days). This study provides a new strategy for the fabrication of novel controlled-release fertilizers.

Received 1st September 2019 Accepted 3rd October 2019

DOI: 10.1039/c9ra06939a

rsc.li/rsc-advances technique in developing countries, which have rapidly increasing population that place significant strain on food demand. Second, fertilizer application can theoretically be guided more accurately using fertilizer and water control technology, soil testing formula fertilization technology, and balanced fertilization. However, these measures not only increase the human cost of fertilizer application but also make it difficult to popularize such technologies, particularly in China where the land is broadly distributed. Third, precise nutrient management technology in farmlands has broad prospects, but it is still in the research stage.

Controlled-release fertilizers provide a new method to solve low nutrient utilization rates. ${ }^{6,7}$ Currently, most of the controlled-release fertilizers used are coated with organic polymers, such as polyolefins, dicyclopentadiene, polystyrene, polysulfones, and glyceride. ${ }^{8-10}$ However, the high cost and complex production process of these materials limit their largescale application in controlled-release fertilizers. ${ }^{11}$ In addition, these polymer materials can potentially harm the soil ecological environment. Relevant studies have shown that the accumulation of such materials in the soil not only reduces soil fertility but may also release toxic gases when they degrade. ${ }^{12}$ Some natural materials, such as chitosan, starch and lignin, have multiple advantages including easy availability, eco-friendly, a low-cost and biodegradability. ${ }^{\mathbf{1 3 , 1 4}}$ Meanwhile, these materials also have many negative characteristics. For instance, chitosan is only soluble in diluted acid, making it difficult to prepare water-soluble chitosan derivatives; otherwise, chitosan is dissolved in organic solvents, which not only increases the costs, but also causes serious environmental concerns. ${ }^{15-17}$ Starch exhibits a poor water resistance and film-forming ability, and is easily degraded in soil. ${ }^{\mathbf{1 8}, 19}$ Lignin has complex components, making its fabrication difficult. ${ }^{20,21}$ Therefore, it is
${ }^{a}$ The State Key Laboratory of Soil and Sustainable Agriculture, Institute of Soil Science, Chinese Academy of Sciences, Nanjing 210008, China. E-mail: chwdu@issas.ac.cn; Tel: +86-25-86881565

${ }^{b}$ College of Modern Agricultural Sciences, University of Chinese Academy of Sciences, Beijing 100049, China

$\dagger$ Electronic supplementary information (ESI) available. See DOI: 10.1039/c9ra06939a 
necessary to develop low-cost and environmentally friendly controlled-release fertilizers.

Metal-organic frameworks (MOFs) are materials with adjustable pore sizes that are formed via the self-assembly of metal ions or metal ion clusters with organic ligands. MOFs have been applied in many fields, such as gas storage, ${ }^{22-24}$ catalysis, ${ }^{25}$ and drug carriers. ${ }^{26-28}$ In agricultural programs, studies on the application of Fe-based MOFs as Fe fertilizers in kidney bean crops have shown that they can improve the growth, chlorophyll content, protein, and enzyme activity of kidney beans. ${ }^{29}$ The impact of synthesized oxalate-phosphateamine metal-organic frameworks (OPA-MOFs) ( $\mathrm{N}$ content: $3.1 \%$ ) on the growth, nutrient uptake, and grain yield of wheat has been investigated. The results indicated that OPA-MOF could be used as a novel efficiency-enhancing nitrogen fertilizer. ${ }^{30,31}$ Further, a MOF containing $5.16 \% \mathrm{~N}$ and $14.1 \% \mathrm{P}$ was synthesized, and its degradation behavior in farmland soil was explored. The results revealed that the MOF material degraded by $50.9 \%$ throughout a wheat season, and exhibited a slow nutrient release rate. ${ }^{32}$ Although these materials show potential as controlled-release fertilizers, they are low in $\mathrm{N}$ content, which is likely to limit their application in agriculture. Therefore, in this work, we chose an eco-friendly organic ligand and developed two novel MOFs with relatively high nutrient contents.

The objective of this work was to synthesize two new MOF compounds using a hydrothermal synthetic route by optimizing the process conditions and components, using non-toxic ferric chloride and phosphoric acid as the inorganic reagents, citric acid as the organic ligand, and urea as the structure-directing agent (SDA), to achieve controlled release of nutrients, to improve nutrient utilization, and to reduce environmental risks.

\section{Experimental section}

\section{Materials}

Ferric chloride $\left(\mathrm{FeCl}_{3} \cdot 6 \mathrm{H}_{2} \mathrm{O}\right)$, citric acid $\left(\mathrm{H}_{8} \mathrm{C}_{6} \mathrm{O}_{7} \cdot \mathrm{H}_{2} \mathrm{O}\right)$, phosphoric acid $\left(\mathrm{H}_{3} \mathrm{PO}_{4}\right)$, and urea $\left(\mathrm{CO}\left(\mathrm{NH}_{2}\right)_{2}\right)$ were of analytical grade and purchased from Nanjing Ronghua Scientific Equipment Co., Ltd. (Jiangsu, China). Deionized water was used throughout the experiments (pH: 6.9; resistance: 18.2 $\left.\mathrm{M} \Omega \mathrm{cm}^{-1}\right)$. A KCF-2 autoclave was employed in the experiments (Beijing Century Senlang Experimental Apparatus Co., China).

\section{Synthesis of compound I and compound II}

For compound I, $0.25 \mathrm{~mol}$ ferric chloride, $1.125 \mathrm{~mol}$ phosphoric acid, $0.375 \mathrm{~mol}$ citric acid, and $0.75 \mathrm{~mol}$ urea were dissolved in $292.5 \mathrm{~mL}$ of deionized water in a beaker, and mixed evenly. Therefore, the molar ratio of the components in solution was ferric chloride : phosphoric acid : citric acid : urea : deionized water $=1: 4.5: 1.5: 3: 65$. The mixture was transferred to a KCF-2 autoclave with the stirring speed set to $80 \mathrm{rpm}$, and was held in the autoclave at $115^{\circ} \mathrm{C}$ for $18 \mathrm{~h}$. The obtained product was washed three times with deionized water, and subsequently dried at $60{ }^{\circ} \mathrm{C}$. The molar ratio for synthesizing compound II was ferric chloride : phosphoric acid : citric acid : urea : deionized water $=$ $1: 4.5: 1.5: 4.5: 65$. The procedure was the same as that for compound I.

\section{Characterization}

The structures of the compounds were determined using a Fourier-transform infrared spectroscopy Nicolet 6700 spectrometer (Thermo Electron Scientific Instruments Corporation, Madison, WI, USA) equipped with a model 300 photoacoustic cell (FTIR-PAS) (MTEC Photoacoustics, Inc., Oakland, California, USA) and an attenuated total reflection Fouriertransform infrared spectroscopy (ATR-FTIR) instrument (4300 Handheld FTIR, Agilent Technologies, USA). The surface morphologies were obtained using a MERLIN field emissionscanning electron microscope (FE-SEM) (Carl Zeiss Microscopy GmbH, Jena, Germany), and the surface elemental compositions and distribution were analyzed using a Thermo Fisher 250Xi X-ray photoelectron spectrometer (XPS) and an energy-dispersive spectroscopy (EDS) detector attached to the SEM. The powder X-ray diffraction (PXRD) data were collected in the $5-80^{\circ}$ range using an ARL X'TRA diffractometer (Thermo Electron Corporation, Switzerland). The elemental compositions were measured by laser-induced breakdown spectroscopy (LIBS) with a MobiLIBS system (IVEA, France), an iCAP 7000 inductively-coupled plasma optical emission spectrometer (ICPOES, Thermo Fisher Scientific, USA), and a CHN-O-Rapid elemental analyzer (Heraeus, Germany).

\section{Nutrient release behavior in water}

A $3 \mathrm{~g}$ sample of each compound was immersed in $100 \mathrm{~mL}$ of deionized water at $25{ }^{\circ} \mathrm{C}$. The solution $(100 \mathrm{~mL})$ was removed after $20,40,60,80$, and 100 days and replaced with $100 \mathrm{~mL}$ of deionized water for each of the three replicates. The $\mathrm{NH}_{4}{ }^{+}-\mathrm{N}$ and $\mathrm{NO}_{3}{ }^{-}-\mathrm{N}$ contents were measured using a SmartChem 200 discrete auto analyzer (AMS Alliance, Frepillon, France). The urea content was determined by the para-dimethylaminobenzaldehyde colorimetric method (Epoch microplate spectrophotometer, BioTek). The $\mathrm{P}$ content was determined using an iCAP 7000 ICP-OES spectrometer (Thermo Fisher Scientific, USA). The total Fe, $\mathrm{Fe}^{2+}$, and $\mathrm{Fe}^{3+}$ contents were measured by $O$ phenanthroline colorimetry. The $\mathrm{pH}$ values of the soil samples were determined using a $\mathrm{pH}$ meter (Orion Star A211, Thermo Fisher, USA). The nutrient release behaviors were estimated via the nutrient cumulative release rates.

\section{Soil incubation}

Soil incubation experiments were conducted to examine the nutrient release behaviors of both compounds using paddy soil. The soil samples were air-dried to $20 \%$ moisture content and sieved to $3 \mathrm{~mm}$, and then dried to constant weights at $50{ }^{\circ} \mathrm{C}$. The soil physicochemical properties were as follows: organic matter, $18.25 \mathrm{~g} \mathrm{~kg}^{-1}$; total-N, $1.23 \mathrm{~g} \mathrm{~kg}^{-1} ; \mathrm{NH}_{4}{ }^{+} \mathrm{N}, 12.15 \mathrm{mg} \mathrm{kg}^{-1} ; \mathrm{NO}_{3}{ }^{-}-$ $\mathrm{N}, 14.33 \mathrm{mg} \mathrm{kg}{ }^{-1}$; available $\mathrm{P}, 17.65 \mathrm{mg} \mathrm{kg}{ }^{-1}$; available Fe, $7.95 \mathrm{mg} \mathrm{kg}^{-1}$; and $\mathrm{pH}, 6.58$. The soil samples (100 g) were placed in $8 \mathrm{~cm}$-diameter pots, and the moisture was adjusted to $38 \%(\mathrm{w} / \mathrm{w})$ in each pot. Three treatments were prepared: (1) 
control treatment (with no fertilizer); (2) compound I treatment, which involved an application of $75 \mathrm{~kg} \mathrm{~N} \mathrm{ha}^{-1}$ (compound I N content: 9.5\%); and (3) compound II treatment, which also involved an application of $75 \mathrm{~kg} \mathrm{~N} \mathrm{ha}{ }^{-1}$ (compound II N content: $10.78 \%$ ). Three replicates were conducted for each treatment. All the pots were placed in a shade house and were loosely covered with plastic wrap to reduce soil water evaporation. The soil samples were collected at different time intervals $(20,40,60,80$, and 100 days) for a total of 45 pots. The mineral $\mathrm{N}$ $\left(\mathrm{NH}_{4}{ }^{+} \mathrm{N}\right.$ and $\left.\mathrm{NO}_{3}{ }^{-} \mathrm{N}\right)$ contents were determined using a SmartChem 200 discrete auto analyzer (AMS Alliance, Frepillon, France). The available $\mathrm{P}$ and available Fe were measured using an iCAP 7000 ICP-OES spectrometer (Thermo Fisher Scientific, USA). The soil $\mathrm{pH}$ was measured using a $\mathrm{pH}$ meter (Orion Star A211, Thermo Fisher Scientific, USA). The N, P, and Fe cumulative release rates from the MOF compounds were assessed by the ratios of mineral $\mathrm{N}$ in the soil (in the $\mathrm{NH}_{4}{ }^{+} \mathrm{N}$ and $\mathrm{NO}_{3}{ }^{-} \mathrm{N}$ fractions), available $\mathrm{P}$, and available Fe contents, to the corresponding initial nutrient applications.

\section{Results and discussion}

To confirm the formation of compounds I and II during the hydrothermal reaction, the ATR-FTIR (Fig. 1A) and FTIR-PAS (Fig. 1B) spectra of the two compounds were recorded. As shown in the spectra, both compounds show the same
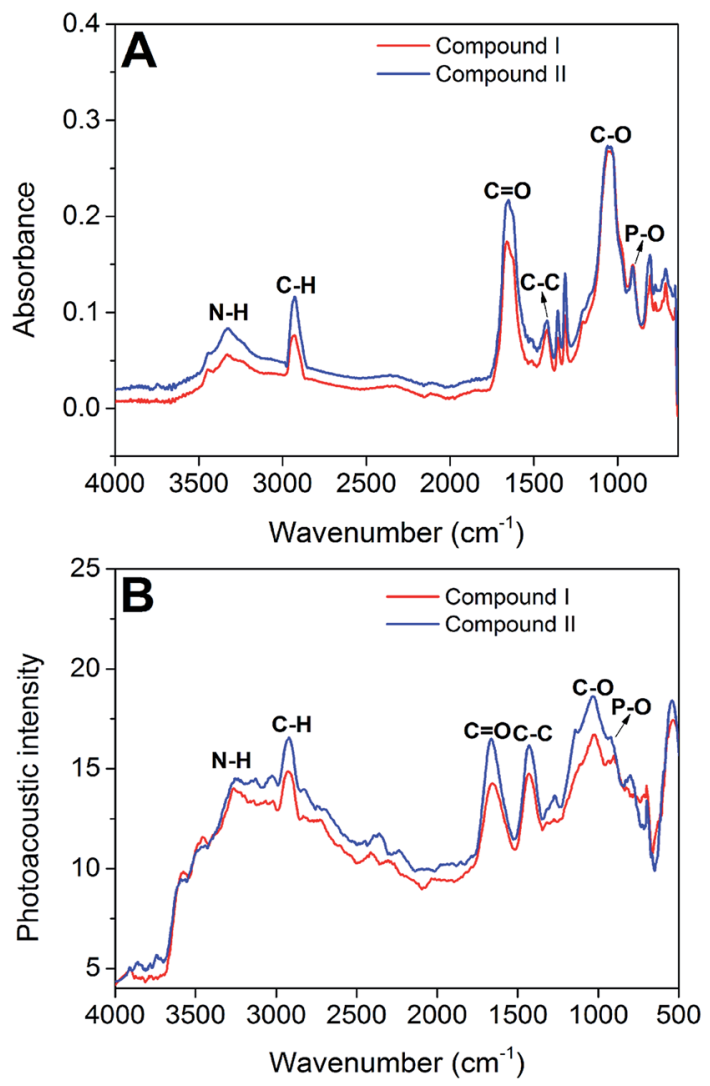

Fig. 1 Structural characterizations of the two compounds by ATRFTIR spectra (A) and FTIR-PAS spectra (B). characteristic peaks. The broad peak at approximately $3365 \mathrm{~cm}^{-1}$ was associated with the $\mathrm{N}-\mathrm{H}$ stretching vibration, indicating that the urea group was involved in the formation of the two compounds. The peaks at 2925, 1654, 1431, and $1022 \mathrm{~cm}^{-1}$ were assigned to $\mathrm{C}-\mathrm{H}, \mathrm{C}=\mathrm{O}, \mathrm{C}-\mathrm{C}$, and $\mathrm{C}-\mathrm{O}$ stretching vibrations, respectively, revealing that citric acid groups were successfully introduced into the two compounds. In the fingerprint region, the peak at $902 \mathrm{~cm}^{-1}$ was attributed to the $\mathrm{P}-\mathrm{O}$ stretching vibration, implying that phosphoric acid was involved in the hydrothermal reaction and was also a part of the two compounds.

XPS was used to investigate the elemental compositions and bonding configurations of the compounds, as shown in Fig. $2 \mathrm{~A}_{1}$. Five peaks at approximately $724,532,402,285$, and $134 \mathrm{eV}$, respectively corresponding to $\mathrm{Fe} 2 \mathrm{p}_{1 / 2}, \mathrm{O} 1 \mathrm{~s}, \mathrm{~N} 1 \mathrm{~s}, \mathrm{C} 1 \mathrm{~s}$, and $\mathrm{P} 2 \mathrm{p}$, were observed, indicating that the ferric chloride, citric acid, urea, and phosphoric acid reagents were involved in the formation of the compounds. Moreover, to further study the chemical bond configuration of compounds, the highresolution characteristic peaks of both compounds were deconvoluted. $\mathrm{Fe}^{3+}(712 \mathrm{eV}), \mathrm{Fe}^{2+}(709.2 \mathrm{eV})$, and RO-Fe (533.2 $\mathrm{eV}$ ) revealed the valence state and chemical bonding of Fe in compound I (Fig. $2 \mathrm{~A}_{2}$ and $\mathrm{A}_{3}$ ), and mixed-valence $\mathrm{Fe}^{3+} / \mathrm{Fe}^{2+}$ MOFs have been previously reported. ${ }^{33,34}$ The peak at $401.98 \mathrm{eV}$ was assigned to $\mathrm{NH}_{4}{ }^{+}$(Fig. $2 \mathrm{~A}_{4}$ ), implying that the decomposition of urea occurred during the hydrothermal reaction.

In this work, urea was used as a SDA, which influenced the structure of the target products, and also the resulting stability of the obtained compounds. For most MOFs synthesized using amine-based SDAs, the SDAs usually remain essentially unchanged and exist as guests in the framework pores. In some cases, however, the SDAs fully or partially decompose to more stable secondary structures, as shown in previous studies..$^{30,35,36}$ The $\mathrm{O}-\mathrm{C}=\mathrm{O}(290.38 \mathrm{eV}), \mathrm{C}=\mathrm{O}(288.78 \mathrm{eV}), \mathrm{C}-\mathrm{O}(286.18 \mathrm{eV})$, and $\mathrm{C}-\mathrm{C}(284.68 \mathrm{eV})$ peaks in the spectra suggested the successful introduction of citric acid groups (Fig. $2 \mathrm{~A}_{5}$ ), while the peak at $133.7 \mathrm{eV}$ was associated with $\mathrm{P}-\mathrm{O}$ (Fig. $2 \mathrm{~A}_{6}$ ), suggesting that phosphoric acid participated in the MOF formation and became part of its skeleton. The XPS spectra of compound II shows essentially the same features (Fig. $2 \mathrm{~B}_{1}-\mathrm{B}_{6}$ ).

The SEM images with different magnifications were used to observe the surface morphology of the compounds. As shown in Fig. $3 A_{1}-A_{3}$, the surface of compound I was rough and uneven, and contains many massive aggregated crystallites of different sizes. There is a clear difference between the surface structures of the two compounds, and many regular crystal plate-like structures with sharp edges and smooth surfaces are observed in compound II (Fig. $3 \mathrm{~B}_{1}-\mathrm{B}_{3}$ ), indicating that the amount of added urea greatly influenced the compounds' structures. Furthermore, EDS maps were employed to observe the surface elemental compositions and distributions of the compounds. As shown in Fig. $3 \mathrm{~A}_{4}$ and $\mathrm{B}_{4}, \mathrm{Fe}, \mathrm{P}, \mathrm{N}, \mathrm{C}$, and $\mathrm{O}$ were uniformly distributed on the compounds' surfaces, which directly verified that all the reagents were involved in the formation of the two compounds.

PXRD and LIBS were employed to investigate the phase and elemental composition of the two compounds. As shown in 

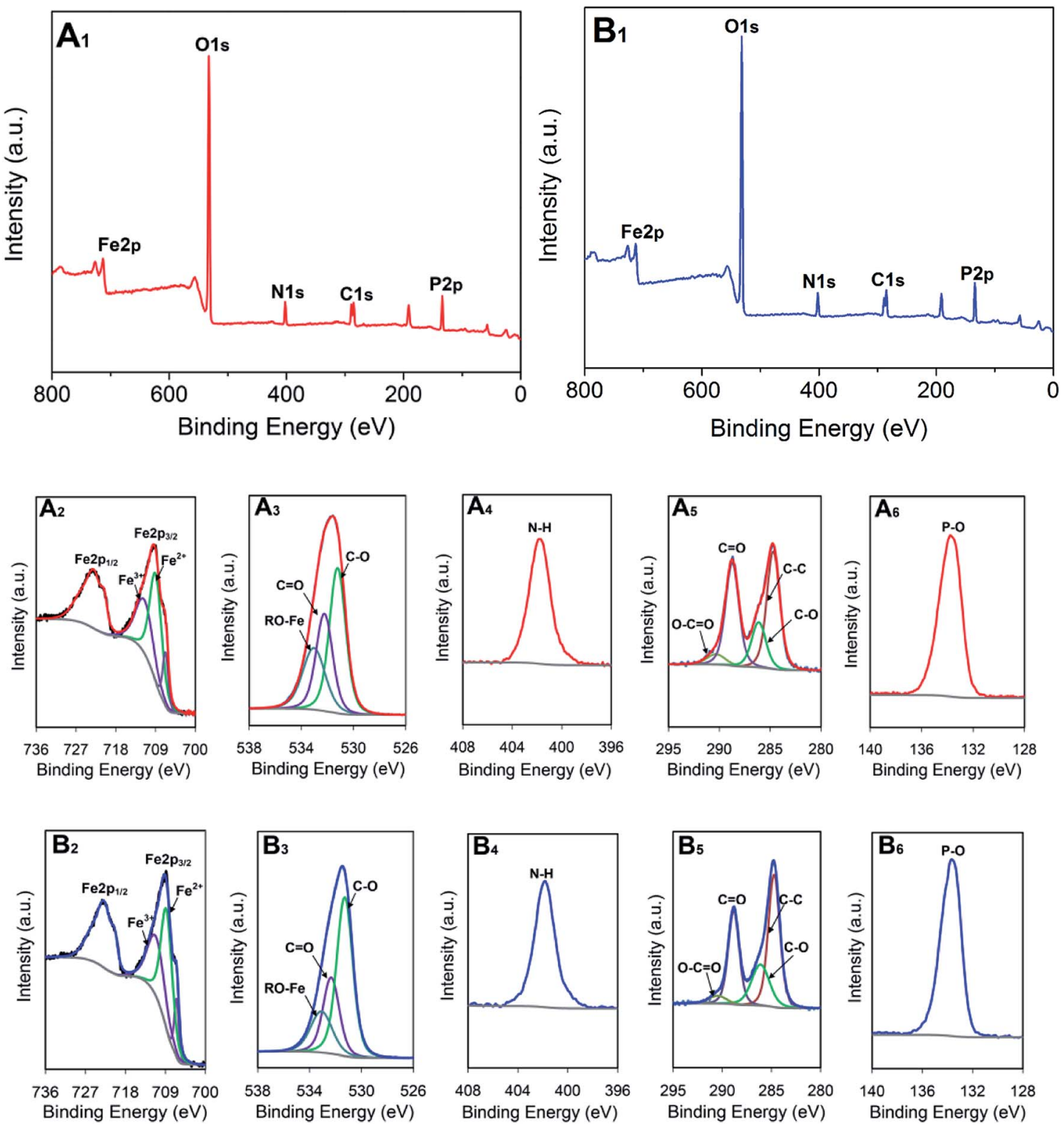

Fig. 2 XPS spectra of compound I $\left(A_{1}-A_{6}\right)$ and compound II $\left(B_{1}-B_{6}\right)$.

Fig. 4A, the characteristic peaks of the two compounds were clearly different, indicating that the urea (SDA) concentration in the reaction solution affected the crystal structure of the product, which is consistent with the results from a previous study. ${ }^{30}$ The PXRD data of the compounds were compared to the International Centre for Diffraction Data (ICDD). Since no match was found, it was suggested that our synthesized compounds are novel MOFs. The LIBS spectra of both compounds showed similar spectral shapes and characteristic peaks (Fig. 4B). The peaks at $274.6 \mathrm{~nm}, 500.3 \mathrm{~nm}$, and $844.8 \mathrm{~nm}$, $777.3 \mathrm{~nm}$, and $655.6 \mathrm{~nm}$ were attributed to the characteristic bands of $\mathrm{Fe}, \mathrm{P}, \mathrm{C}, \mathrm{O}$, and $\mathrm{H}$, respectively, while the peaks at $746.8,819.2$, and $868.3 \mathrm{~nm}$ were assigned to $\mathrm{N}$, this shows that all reagents participated in the formation of the MOFs during the hydrothermal synthesis.
To better understand the elemental compositions and content of both compounds, CHN-O-Rapid elemental analysis and ICP-OES were used to determine the $\mathrm{C}, \mathrm{H}$, and $\mathrm{N}$ contents of the compounds and the elemental content of the solution after the hydrothermal reaction, respectively. As shown in Table 1, the yield of compound I was slightly higher than that of compound II. Compound II contained more Fe, N, and $\mathrm{H}$ than compound I, and less $\mathrm{P}$ and $\mathrm{C}$. These results imply that the concentration of urea (SDA) in the hydrothermal reaction can affect the elemental composition of the products.

The compounds were incubated in water at $25{ }^{\circ} \mathrm{C}$ to study their nutrient release behaviors. As shown in Fig. 5A, compound I gradually changed color from yellow to brownish-red during incubation, while the color change in compound II was not noticeable (Fig. 5B). The $\mathrm{N}$ cumulative release rates of both 

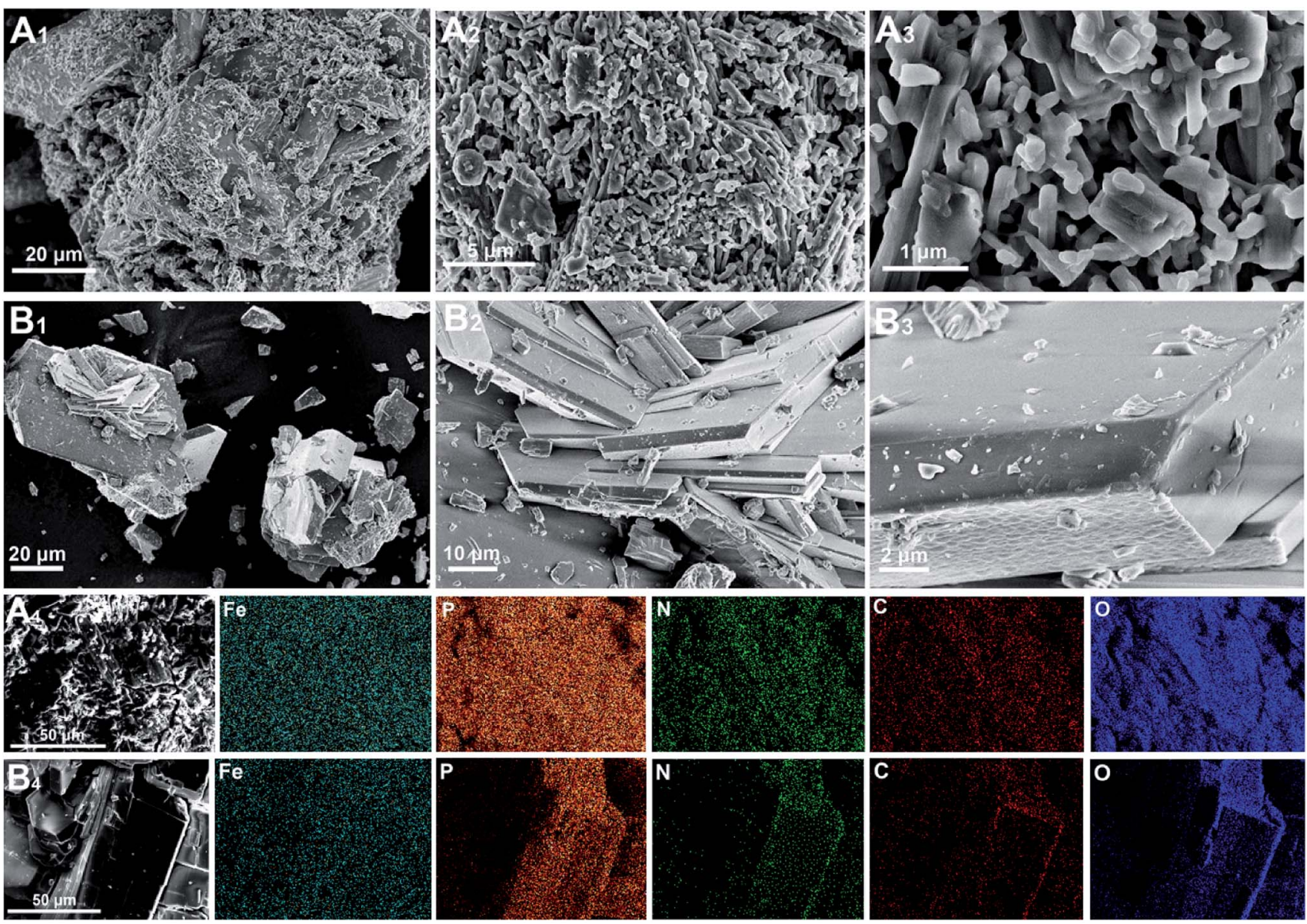

Fig. 3 SEM images of compound I $\left(A_{1}-A_{3}\right)$ and compound II $\left(B_{1}-B_{3}\right)$. EDS elemental maps corresponding to the SEM images of compound I $\left(A_{4}\right)$ and compound $\mathrm{II}\left(\mathrm{B}_{4}\right)$.

compounds at 100 days were $6.78 \%$ and $7.66 \%$, respectively (Fig. 5C), which are both significantly lower than that reported for coated controlled-release fertilizers ( $\mathrm{N}$ cumulative release rate over $80 \%$ within 70 days). ${ }^{37,38}$ Interestingly, the $\mathrm{N}$ in the water was mostly present as $\mathrm{NH}_{4}{ }^{+}-\mathrm{N}$ (Fig. $\mathrm{S} 1 \dagger$ ), while urea and $\mathrm{NO}_{3}{ }^{-}-\mathrm{N}$ were undetected. One reason may be that the water $\mathrm{pH}$ is under acidic conditions, resulting in the predominance of $\mathrm{NH}_{4}{ }^{+} \mathrm{N}$ species; it may also be possible that $\mathrm{N}$ is present in the compound materials as $\mathrm{NH}_{4}{ }^{+}-\mathrm{N}$, which is consistent with a previous study. ${ }^{30}$ However, the cumulative release rates of $\mathrm{P}$ and Fe were lower than that of N (Fig. 5D and E), which is likely due to the structure of the compounds. Fe and $\mathrm{P}$ constituted the framework of the compounds, while SDA (urea) was embedded in the crystal channels as $\mathrm{NH}_{4}{ }^{+} \mathrm{N}$. Therefore, the $\mathrm{P}$ and $\mathrm{Fe}$ nutrient release rates may be inhibited by the strong $\mathrm{P}$ and $\mathrm{Fe}$ bonds in the framework. Furthermore, $\mathrm{Fe}^{3+}$ and $\mathrm{Fe}^{2+}$ were
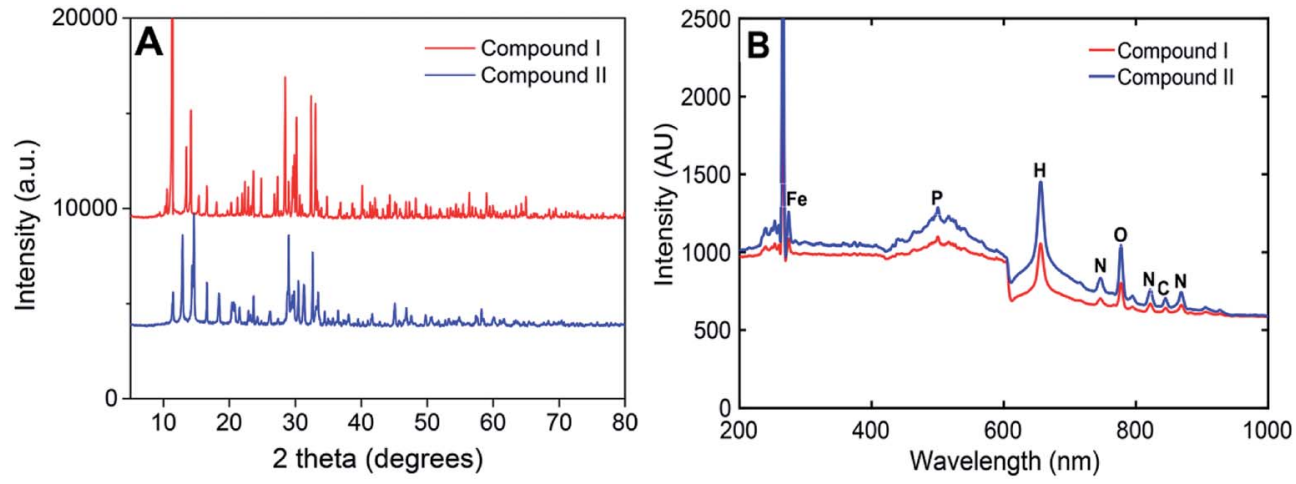

Fig. 4 PXRD (A) and LIBS (B) spectra of compounds I and II. 
Table 1 Yields and elemental composition of both compounds. Yields and elemental compositions (\%)

\begin{tabular}{lll}
\hline & Compound I & Compound II \\
\hline Yields & $35.8 \pm 1.6$ & $32.1 \pm 2.2$ \\
Fe & $14.55 \pm 1.1$ & $16.68 \pm 1.9$ \\
$\mathrm{C}$ & $8.25 \pm 0.26$ & $7.72 \pm 0.18$ \\
$\mathrm{~N}$ & $9.05 \pm 0.11$ & $10.78 \pm 0.20$ \\
$\mathrm{P}$ & $14.92 \pm 1.05$ & $14.10 \pm 1.28$ \\
$\mathrm{H}$ & 2.56 & 3.12
\end{tabular}

detected in the water (Fig. S2 $\dagger$ ). Besides, the water pH slightly declined during the incubation process (Fig. $5 \mathrm{~F}$ ), which is likely attributed to the hydrolysis of $\mathrm{NH}_{4}{ }^{+} \mathrm{N}$. These results suggest that the two compounds have slow nutrient release rates, and may be unable to meet the nutrient requirements of crops when used as controlled-release fertilizers.

To further explore the potential of using the two compounds as controlled-release fertilizers, a soil incubation experiment was conducted to investigate their nutrient release behaviors. For both compounds, the mineral $\mathrm{N}\left(\mathrm{NH}_{4}{ }^{+}-\mathrm{N}\right.$ and $\left.\mathrm{NO}_{3}{ }^{-}-\mathrm{N}\right)$ cumulative release rates over 100 days were $60.2 \%$ and $68.6 \%$, respectively (Fig. 6A). The available $\mathrm{P}$ cumulative release rates of compounds I and II were $42.2 \%$ and $46.8 \%$, respectively (Fig. 6B), while the available Fe cumulative release rates were $22.2 \%$ and $23.6 \%$, respectively (Fig. 6C). Compared to previously reported nutrient release rates (in compounds using oxalic acid as ligands), ${ }^{32}$ the compounds reported here showed higher
A
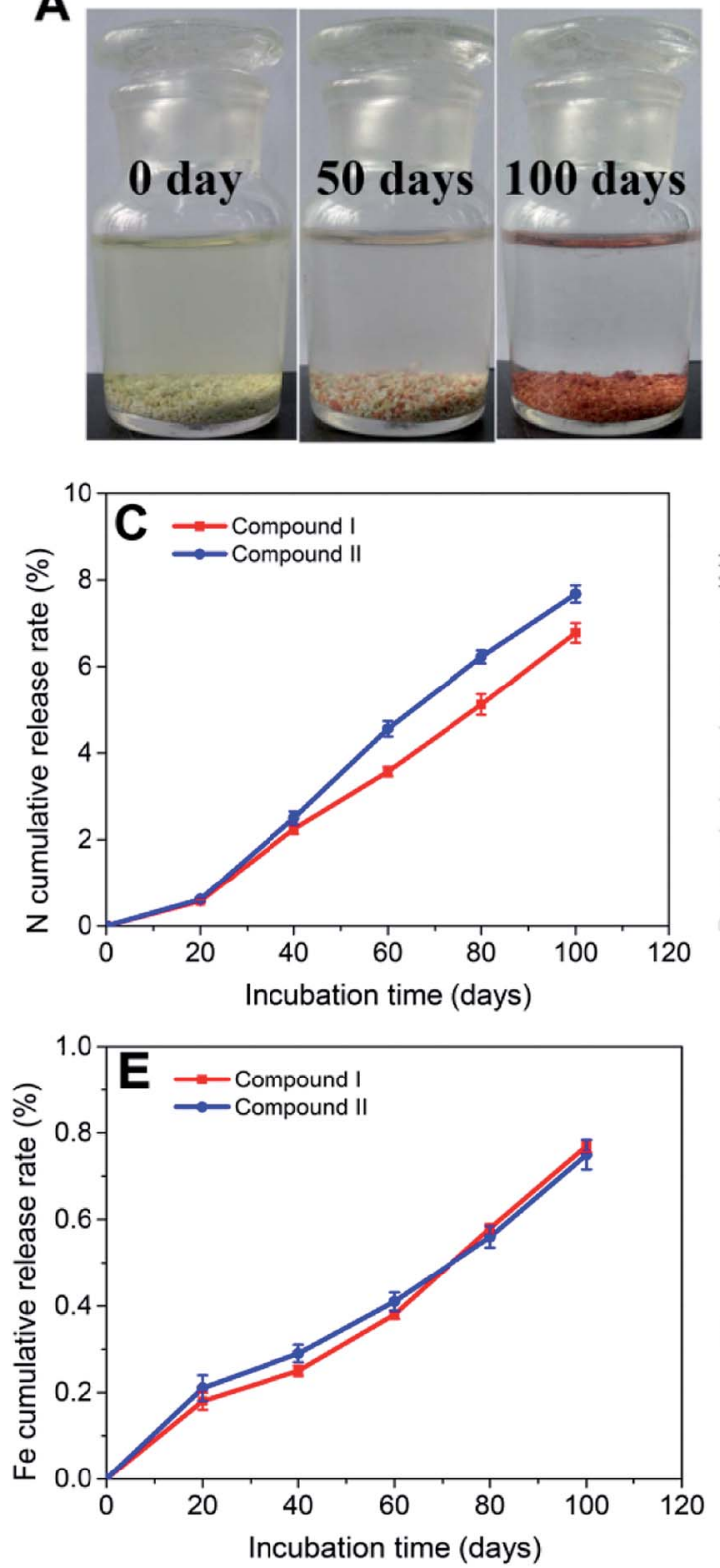

B
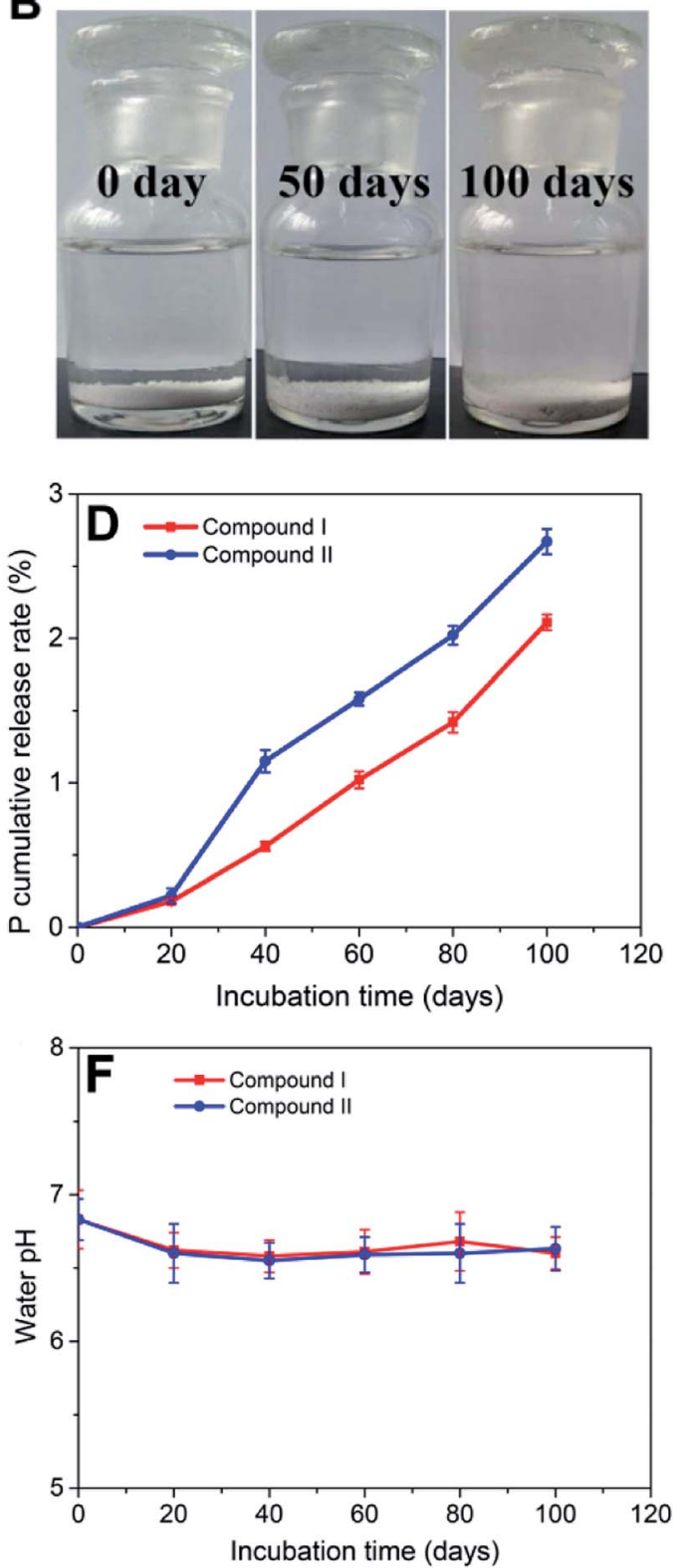

Fig. 5 Change in compound I (A) and compound II (B) amounts during water incubation. N (C), P (D), and Fe (E) cumulative release rates of compound I and compound II at $25^{\circ} \mathrm{C}$ in water. (F) Effects of the compounds on the water $\mathrm{pH}$. 

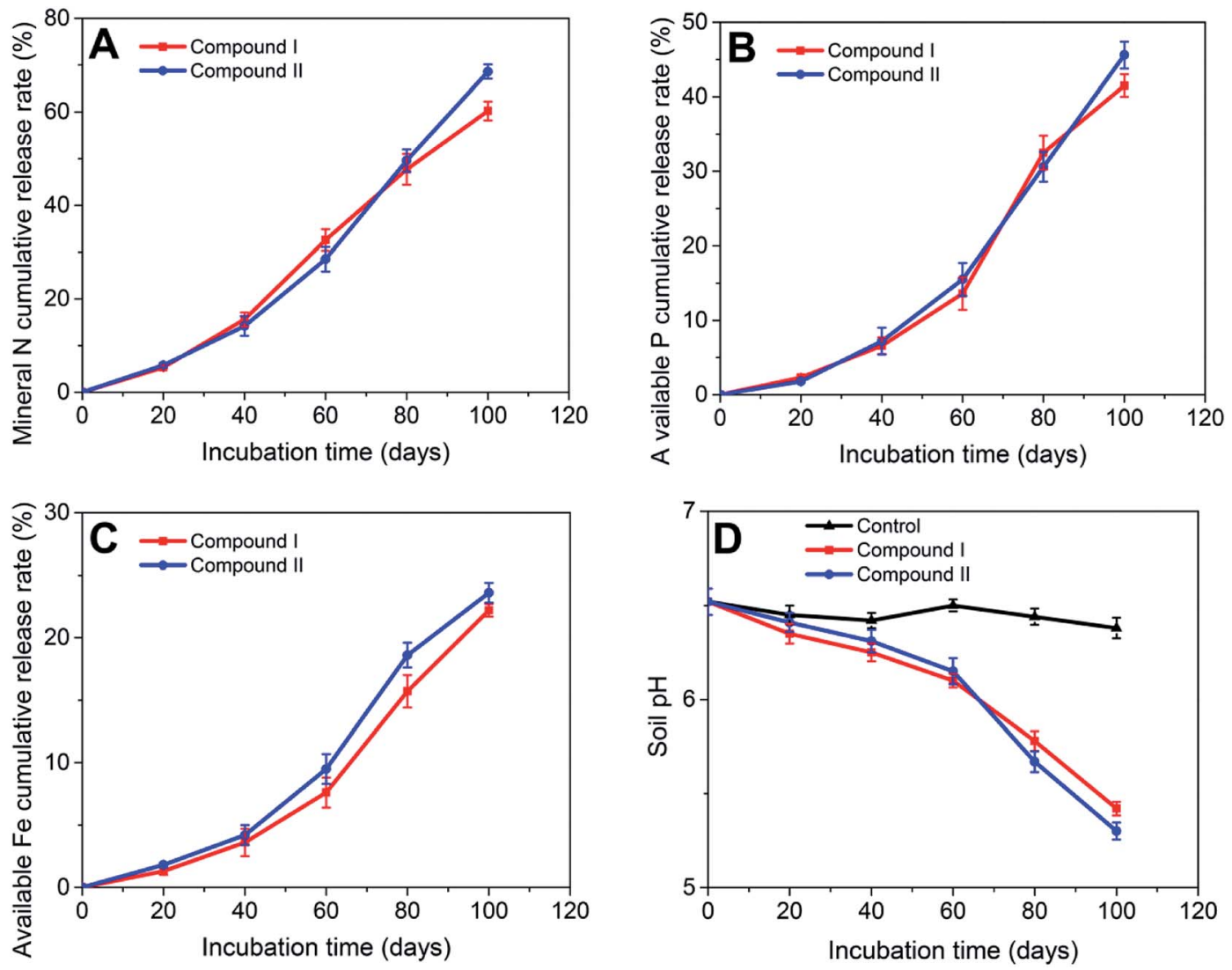

Fig. 6 Effects of the compounds on the soil nutrients. (A) Mineral $\mathrm{N}\left(\mathrm{NH}_{4}{ }^{+}-\mathrm{N}\right.$ and $\left.\mathrm{NO}_{3}{ }^{-}-\mathrm{N}\right)$ cumulative release rates; (B) available $\mathrm{P}$ cumulative release rates; (C) available Fe cumulative release rates; and (D) soil $\mathrm{pH}$.

nutrient release rates. This result is likely due to the difference between ligands. The citric acid used in this study is a low molecular weight organic acid widely found in soil, which exhibits a lower sorption in soil and higher biodegradability than that of oxalic acid. ${ }^{39-42}$ Therefore, the MOF compounds using citric acid as organic ligands were more susceptible to mineralization by microorganisms. Additionally, in comparison to that of the control group, the $\mathrm{pH}$ of the soil treated with the compounds decreased during incubation (Fig. 6D), which was likely due to the redox-induced oxidation of the structural $\mathrm{Fe}^{2+}$ in the compounds. The XPS, water incubation, and soil incubation results all indicated that a part of $\mathrm{Fe}$ in the compounds was present as $\mathrm{Fe}^{2+}$, which is supported by previous studies. ${ }^{30,33,43}$ Therefore, $\mathrm{Fe}^{2+}$ oxidation is the preferred reaction because $\mathrm{Fe}^{2+} / \mathrm{Fe}^{3+}$ has a higher redox-potential compared to that of $\mathrm{NH}^{4+}$ nitrification, resulting in the release of $2 \mathrm{H}^{+}$for each oxidized Fe atom. ${ }^{44}$ Moreover, this oxidation process limits the nitrification.

\section{Conclusions}

Two novel MOF compounds rich in N, P, and Fe nutrients were successfully fabricated via hydrothermal synthesis. The characterization results showed that urea (SDA) affected the structure of the products, and all the reagents participated in the formation of the compounds. Water incubation and soil incubation were employed to investigate the nutrient release behaviors of the compounds. Consequently, the compounds showed much better release performance when placed in soil than when placed in water, and both compounds lasted longer than 100 days. Therefore, these novel MOF materials can provide new strategies for the development of controlled-release fertilizers in the future.

\section{Conflicts of interest}

The authors declare no competing financial interest.

\section{Acknowledgements}

This work was supported by the National Key Research and Development Program of China (2017YFD0200704), the Key Research and Development Program of Jiangsu Province (BE2017388) and the "STS" project from Chinese Academy of Sciences (KFJ-STS-QYZX-046, KFJ-PTXM-003).

\section{References}

1 Y. C. Yang, M. Zhang, Y. C. Li, X. H. Fan and Y. Q. Geng, Soil Sci. Soc. Am. J., 2012, 76, 2307-2317.

2 U. Shavit, A. Shaviv, G. Shalit and D. Zaslavsky, J. Controlled Release, 1997, 43, 131-138. 
3 J. Shen, R. Li, F. Zhang, C. Tang and Z. Rengel, Field Crop. Res., 2004, 86, 225-238.

4 X. Yan, J. Y. Jin, P. He and M. Z. Liang, Agric. Sci. China, 2008, 7, 469-479.

5 A. T. M. A. Choudhury and I. R. Kennedy, Commun. Soil Sci. Plant Anal., 2005, 36, 1625-1639.

6 M. Zhang, Y. C. Yang and Y. X. Shi, Chem. Fert. Ind., 2001, 32, 25-27.

7 S. P. Jin, G. R. Yue, L. Feng, Y. Q. Han, X. H. Yu and Z. H. Zhang, J. Agric. Food Chem., 2011, 59, 322-327.

8 S. K. Jain, G. P. Agrawal, M. Kumar and N. Anande, Pharma Rev., 2007, 5, 1-7.

9 A. Shaviv, Proc. - Int. Fert. Soc., 2001, 469, 1-23.

10 M. Tomaszewska and A. Jarosiewicz, J. Agric. Food Chem., 2002, 50, 4634-4639.

11 Y. S. Ye, X. Q. Liang, Y. X. Chen, J. Liu, J. T. Gu, R. Guo and L. Li, Field Crop. Res., 2013, 144, 212-224.

12 D. Briassoulis and C. Dejean, J. Polym. Environ., 2010, 18, 384-400.

13 A. Wezel, M. Casagrande, F. Celette, J.-F. Vian, A. Ferrer and J. Peigné, Agron. Sustainable Dev., 2014, 34, 1-20.

14 A. Schneider Teixeira, L. Deladino and N. Zaritzky, ACS Sustainable Chem. Eng., 2016, 4, 2449-2458.

15 A. Rattanamanee, H. Niamsup, L. O. Srisombat, W. Punyodom, R. Watanesk and S. Watanesk, J. Polym. Environ., 2014, 23, 334-340.

16 B. R. dos Santos, F. B. Bacalhau, T. dos Santos Pereira, C. F. Souza and R. Faez, Carbohydr. Polym., 2015, 127, 340346.

17 T. Jamnongkan and S. Kaewpirom, J. Polym. Environ., 2010, 18, 413-421.

18 J. Ge, R. Wu, X. Shi, H. Yu, M. Wang and W. Li, J. Appl. Polym. Sci., 2002, 86, 2948-2952.

19 D. Qiao, H. Liu, L. Yu, X. Bao, G. P. Simon, E. Petinakis and L. Chen, Carbohydr. Polym., 2016, 147, 146-154.

20 M. Fernández-Pérez, F. Garrido-Herrera, E. González-Pradas, M. Villafranca-Sánchez and F. Flores-Céspedes, J. Appl. Polym. Sci., 2008, 108, 3796-3803.

21 W. Mulder, R. Gosselink, M. Vingerhoeds, P. Harmsen and D. Eastham, Ind. Crops Prod., 2011, 34, 915-920.

22 M. Eddaoudi, L. Hailian and O. M. Yaghi, J. Am. Chem. Soc., 2000, 122, 1391-1397.

23 S. Kitagawa, R. Kitaura and S. Noro, Angew. Chem., Int. Ed. Engl., 2004, 43, 2334-2375.
24 L. J. Murray, M. Dinca and J. R. Long, Chem. Soc. Rev., 2009, 38, 1294-1314.

25 D. Farrusseng, S. Aguado and C. Pinel, Angew. Chem., Int. Ed. Engl., 2009, 48, 7502-7513.

26 C. Janiak, Dalton Trans., 2003, 14, 2781-2804.

27 U. Mueller, M. Schubert, F. Teich, H. Puetter, K. SchierleArndt and J. Pastre, J. Mater. Chem., 2006, 16, 626-636.

28 A. C. McKinlay, R. E. Morris, P. Horcajada, G. Férey, R. Gref, P. Couvreur and C. Serre, Angew. Chem., Int. Ed., 2010, 49, 6260-6266.

29 R. M. Abdelhameed, R. E. Abdelhameed and H. A. Kamelc, Mater. Lett., 2019, 237, 72-79.

30 M. Anstoetz, N. Sharma, M. Clark and L. H. Yee, J. Mater. Sci., 2016, 51, 9239-9252.

31 M. Anstoetz, T. J. Rose, M. W. Clark, L. H. Yee, C. A. Raymond and T. Vancov, PLoS One, 2015, 10, 1-16.

32 K. Wu, C. W. Du, F. Ma, Y. Z. Shen, D. Liang and J. M. Zhou, Polymers, 2019, 11, 947.

33 Y. C. Jiang, S. L. Wang, K. H. Lii, N. Nguyen and A. Ducouret, Chem. Mater., 2003, 15, 1633-1638.

34 J. R. D. Debord, W. M. Reiff, C. J. Warren, R. C. Haushalter and J. Zubieta, Chem. Mater., 1997, 9, 1994-1998.

35 N. Rajic, D. Stojakovic, D. Hanzel and V. Kaucic, J. Serb. Chem. Soc., 2004, 69, 179-185.

36 K. Abu-Shandi, H. Winkler, B. Wu and C. Janiak, CrystEngComm, 2003, 5, 180-189.

37 Y. Z. Shen, C. W. Du, J. M. Zhou and F. Ma, Sci. Rep., 2018, 8, 12279.

38 J. Z. Xie, Y. C. Yang, B. Gao, Y. S. Wan, C. Y. Li, J. Xu and Q. H. Zhao, ACS Appl. Mater. Interfaces, 2017, 9, 15868-15879.

39 K. Fujii, M. Aoki and K. Kitayama, Soil Biol. Biochem., 2013, 56, 3-9.

40 K. Fujii, C. Hayakawa, P. A. W. VanHees, S. Funakawa and T. Kosaki, Plant Soil, 2010, 334, 475-489.

41 D. L. Jones and D. S. Brassington, Eur. J. Soil Sci., 1998, 49, 447-455.

42 L. Ström, A. G. Owen, D. L. Godbold and D. L. Jones, Soil Biol. Biochem., 2001, 33, 2125-2133.

43 M. Clemente-Leon, E. Coronado, M. C. Gimenez-Lopez, A. Soriano-Portillo, J. C. Waerenborgh, F. S. Delgado and C. Ruiz-perez, Inorg. Chem., 2008, 47, 9111-9120.

44 W. Stumm and J. J. Morgan, Aquatic Chemistry: Chemical Equilibria and Rates in Natural Waters, John Wiley and Sons, 3rd edn, 1995. 